\title{
Optimized Renewable and Sustainable Electricity Generation Systems for Ulleungdo Island in South Korea
}

Kyeongsik Yoo ${ }^{1,2}$, Eunil Park ${ }^{2, *}$, Heetae Kim ${ }^{2}$, Jay Y. Ohm ${ }^{2}$, Taeyong Yang ${ }^{2}$, Ki Joon Kim ${ }^{3, *}$, Hyun Joon Chang ${ }^{2}$ and Angel P. del Pobil ${ }^{3,4, *}$

1 Daejeon Technopark, 694 Taprip-dong, Yuseong-gu, Daejeon 305-510, Korea; E-Mail: ksyoo@djtp.or.kr

2 College of Liberal Arts and Convergence Science, Korea Advanced Institute of Science and Technology (KAIST), 291 Daehak-ro, Yuseong-gu, Daejeon 305-701, Korea;

E-Mails: htya91@kaist.ac.kr (H.K.); johm@kaist.ac.kr (J.Y.O.); tyang@kaist.ac.kr (T.Y.); hjc21c@kaist.ac.kr (H.J.C.)

3 Department of Interaction Science, Sungkyunkwan University, 326 International Hall, Sungkyunkwan-ro 25-2, Jongno-gu, Seoul 110-745, Korea; E-Mail: veritate@skku.edu

4 Department of Computer Science and Engineering, Jaume-I University, Castellon de la Plana 12071, Spain

* Authors to whom correspondence should be addressed; E-Mails: pa1324@kaist.ac.kr (E.P.); veritate@skku.edu (K.J.K.); pobil@uji.es (A.P.P.); Tel.: +82-42-350-4342 (E.P.); Fax: +82-42-350-4340 (E.P.); Tel.: +82-2-740-1867 (K.J.K.); Fax: +82-2-740-1856 (K.J.K.); Tel.: +34-964-72-82-93 (A.P.P.); Fax: +34-964-72-84-86 (A.P.P.).

External Editor: Marc A. Rosen

Received: 17 September 2014; in revised form: 23 October 2014 / Accepted: 3 November 2014 / Published: 6 November 2014

Abstract: The South Korean government has long been attempting to reduce the nation's heavy reliance on fossil fuels and increase environmental safety by developing and installing renewable power generation infrastructures and implementing policies for promoting the green growth of Korea's energy industry. This study focuses on the use of independent renewable power generation systems in the more than 3000 officially affirmed islands off Korea's coast and proposes a simulated solution to the electricity load demand on Ulleungdo Island that incorporates several energy sources (including solar, batteries, and wind) as well as one hydro-electric and two diesel generators. Recommendations based on the simulation results and the limitations of the study are discussed. 
Keywords: HOMER; optimal solution; Ulleungdo Island; renewable energy

\section{Introduction}

While public and industrial awareness of energy and environmental issues has continued to grow, governments across the globe have adopted measures to further the dissemination and diffusion of renewable energy resources [1]. For example, the South Korean government has installed renewable power generation facilities to lower the nation's high dependency on fossil fuels and reduce greenhouse gas emissions [2]. In addition, governments provide financial assistance for the installation of renewable energy facilities to islands that intend to become an independent energy region [3,4]. For example, the local government of Spain's El Hierro Island recently achieved 100\% renewable power generation, providing $158 \%$ of the island's electricity demand. This island, with an area of $278 \mathrm{~km}^{2}$ and a population of 10,000 , constructed a hydro-wind power generation system comprising a hydro station, pumping station, hydro turbines, wind turbines, desalination plants, and upper and lower reservoirs. This system can save about 6000 tons of diesel fuel and eliminate approximately 19,000 tons of carbon dioxide emissions, about 400 tons of nitrogen oxide, about 100 tons of sulfur dioxide, and approximately $7000 \mathrm{~kg}$ of particulate every year [5,6]. As another example, Jeju Island, South Korea's biggest island, officially announced that it would have an independent energy system by 2030 [7]. However, because the island's government is considering only renewable energy facilities, there is no systematic energy solution or even goal for the island.

Moreover, South Korean territory includes over 4000 islands. Establishing self-sufficient renewable power generation systems for them, which will subsequently lower the maintenance costs of the electricity grid between the mainland and the islands, is an urgent energy demand issue for South Korea [8].

This study examines an independent optimized renewable power generation system for a South Korean island using its electricity consumption data. The study focuses on Ulleungdo Island, situated about $140 \mathrm{~km}$ east of the mainland. This study uses the hybrid optimization of multiple energy resources (HOMER) software developed by the National Renewable Energy Laboratory (NREL) to simulate a renewable power generation system for Ulleungdo Island within the limits of the relevant economic parameters, the net present cost (NPC), and the cost of energy (COE). To this end, the following research question is addressed:

Do we propose the optimal and least expensive renewable power generation system, including compared to the current system?

\section{Status of Ulleungdo Island}

\subsection{Location and Population}

Ulleungdo Island is located about $140 \mathrm{~km}$ east of mainland South Korea, at 37.3 north latitude and 130.52 east longitude. The area of the island is about $72.86 \mathrm{~km}^{2}$. Figure 1 shows the geographical location of the island. It comprises about 11,000 residents and 5000 households. 
Figure 1. Geographical location of Ulleungdo Island.

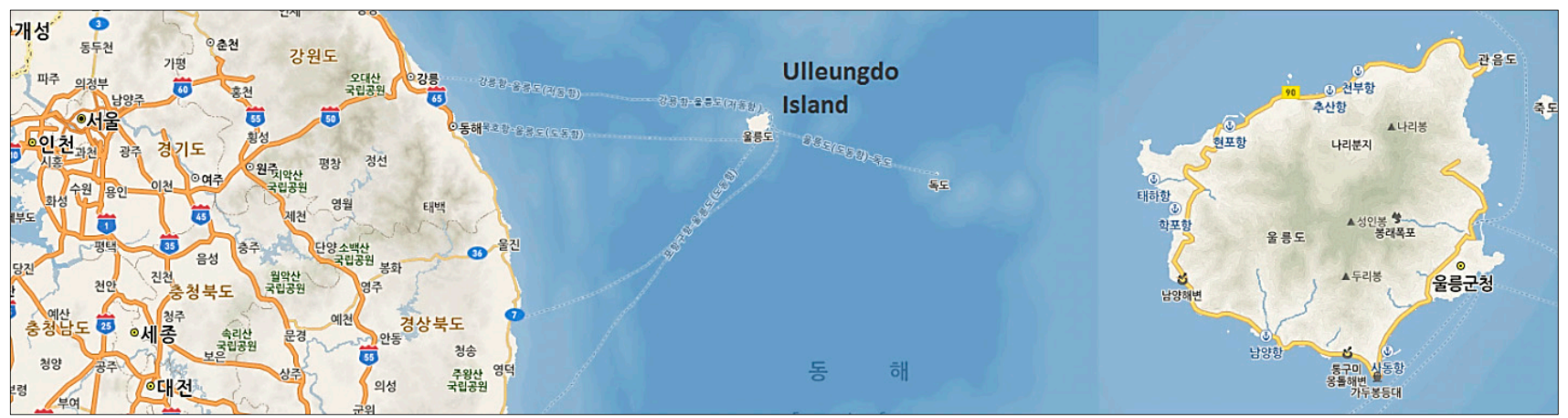

\subsection{Load Information}

The current energy system of the island is powered primarily by two diesel generators $(8000 \mathrm{~kW}$ and $4000 \mathrm{~kW}$ ) and one hydro turbine $(700 \mathrm{~kW})$. Diesel fuel is supplied by the mainland. The Korea Electric Power Corporation (KEPCO) data show that the island's annual electricity use totals 111,000 $\mathrm{kWh} / \mathrm{d}$. Therefore, this study assumes the island's average energy demand to be $4611 \mathrm{kWh}$, with a peak energy demand of $5428 \mathrm{~kW}$; the calculated load factor is 0.849 .

\subsection{Solar Energy}

This study uses solar data collected in 2013 by the Korea Meteorological Administration (KMA) as inputs for the solar clearness and daily radiation indices the HOMER software requires. The average annual solar clearness and average daily radiation are 0.486 and $3.931 \mathrm{kWh} / \mathrm{m}^{2} / \mathrm{d}$, respectively. Figure 2 depicts the island's monthly solar energy production.

Figure 2. Monthly solar energy production on Ulleungdo Island.

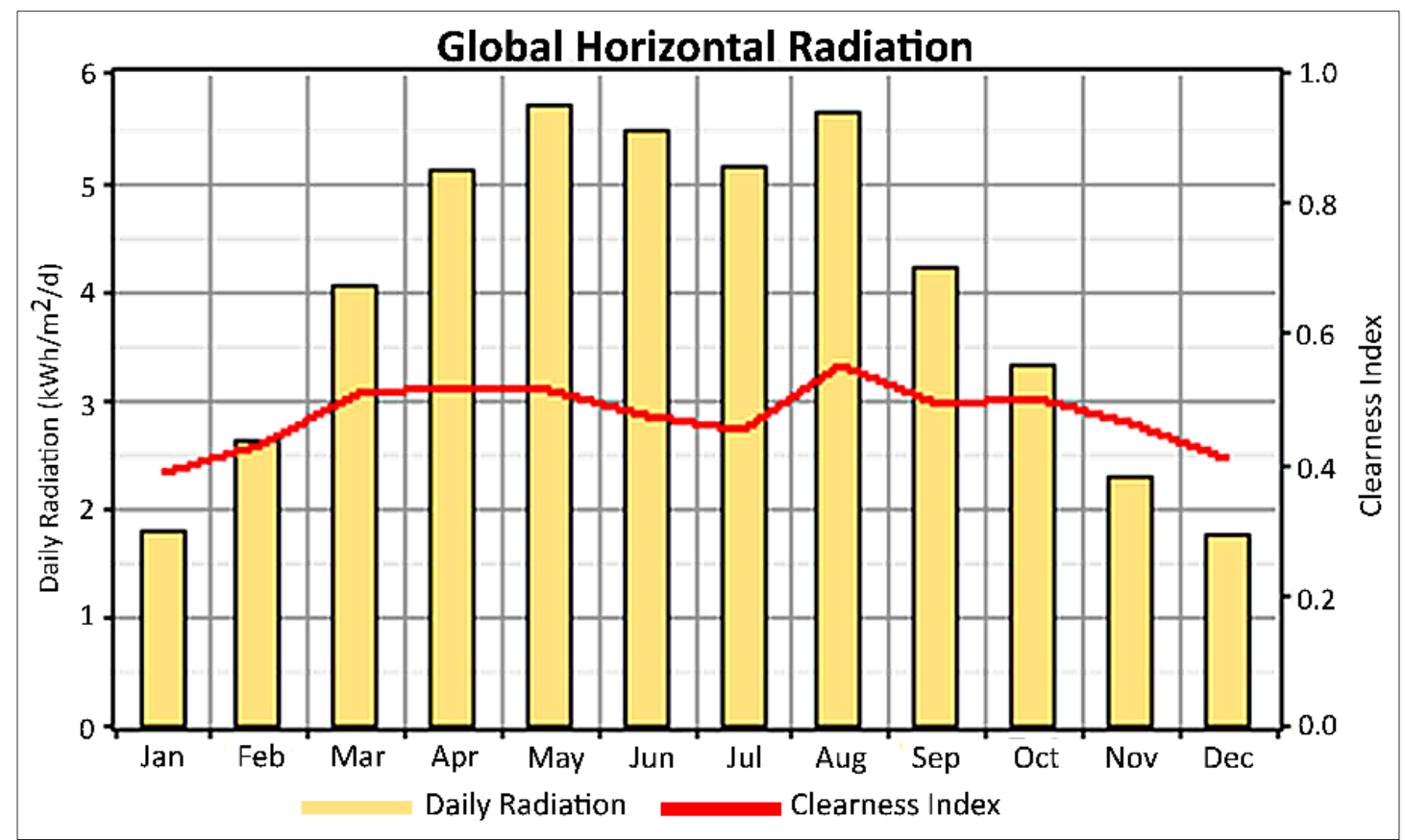




\subsection{Wind Speed}

Data on wind energy collected by the Korea Meteorological Administration (KMA) in 2013 [9] indicate that the island's annual average wind speed is $6.165 \mathrm{~m} / \mathrm{s}$. Figure 3 shows the island's monthly average wind speeds.

Figure 3. Monthly wind speed on Ulleungdo Island.

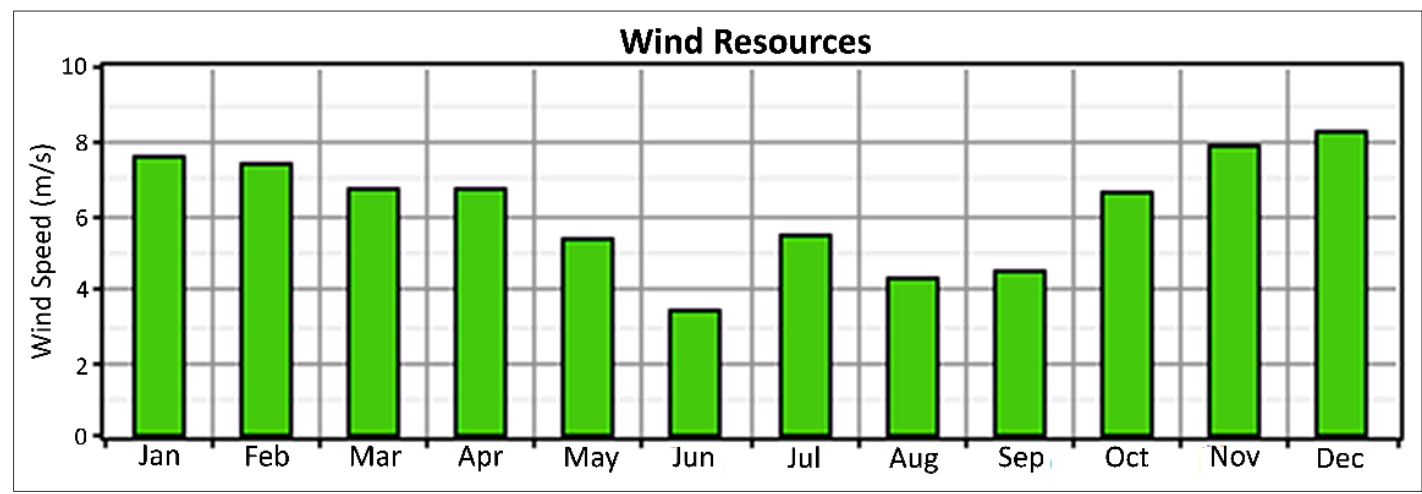

\subsection{Hydro Resources}

A hydro turbine is included in the simulation because one has been consistently used on the island, with an annual average stream flow of $830.3 \mathrm{~L} / \mathrm{s}$.

\section{Key Parameters for the Economic Analysis}

\subsection{Annual Real Interest Rate}

The HOMER software uses the annual real interest rate for greater accuracy. The 2013 annual real interest is obtained from the Bank of Korea [10], and the interest rate $(3.02 \%)$ is calculated using the equations introduced by Dursun [11].

\subsection{Cost of Energy (COE) and Net Present Cost (NPC)}

In general, the COE is the product of the amount of electrical energy produced by the system in $\mathrm{kWh}$ and the system's total annual cost. The total annual cost is the total cost of the system components along with other maintenance costs. The economic feasibility of the system is evaluated based on the COE level.

The NPC is a significant economic output. Previous studies have pointed out that the lifecycle cost fully covers the expense of establishing and operating the system. This study hypothesizes a project lifetime of 20 years.

\subsection{Diesel Price}

Since the island's electricity system is mainly powered by two diesel generators and one hydro turbine, the price of diesel is integral to an economic evaluation of the island's current and future electricity generation systems. The diesel price used for the analysis is $\$ 1.8$ per liter (according to 2014 data provided by the Korea National Oil Corporation and the Bank of Korea) [10]. 
Table 1. Details of the simulation components [7,11-15].

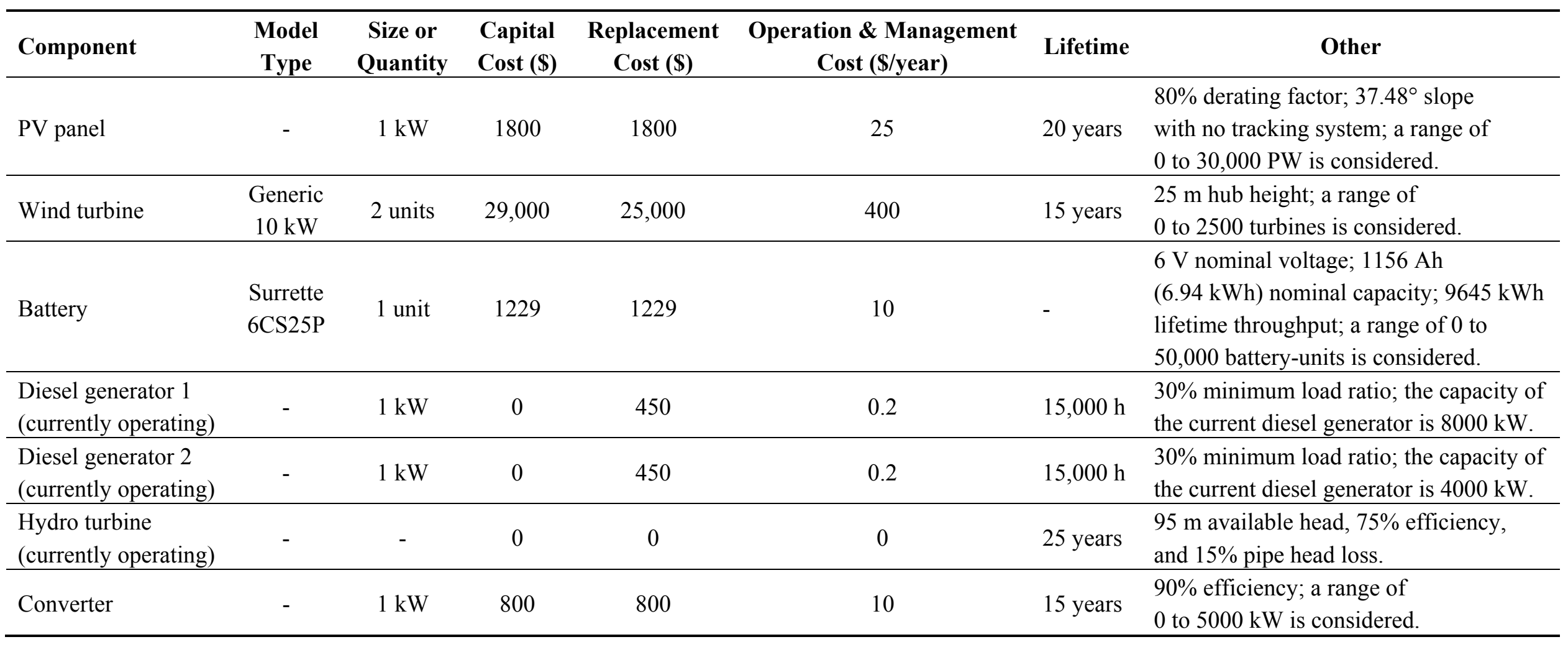




\section{Renewable Power Generation Systems}

The HOMER software requires inputs for the costs of installation, replacement, operation, and management of the system components. Table 1 summarizes the cost of each component.

\section{Results}

This study employs two diesel generators, one hydro turbine, 1725 wind turbines, photovoltaic (PV) panels, a converter, and batteries to build an optimized renewable power generation system on Ulleungdo Island. The simulated optimization results are reported in Table 2. Information on the simulated total and annual cost is presented in Tables 3 and 4, and the electricity production and quantity of system components are reported in Table 5.

Table 2. Proposed renewable power generation system for Ulleungdo Island.

\begin{tabular}{ll}
\hline Components & Index \\
\hline Hydro (kW) & 700 \\
Wind (\# of turbines) & 1725 \\
PV $(\mathrm{kW})$ & 31,065 \\
Diesel generator 1 (currently used, kW) & 8000 \\
Working hours (diesel generator 1) & 64 \\
Diesel generator 2 (currently used, kW) & 4000 \\
Working hours (diesel generator 2) & 474 \\
Consumed diesel (L) & 696,396 \\
Battery (\# of units) & 32,765 \\
Converter (kW) & 5975 \\
Initial Capital (\$) & $125,977,680$ \\
Operating Cost (\$/year) & $6,250,551$ \\
Total NPC (\$) & $234,819,440$ \\
COE (\$/kWh) & 0.334 \\
Ren. Frac. & 0.97 \\
\hline
\end{tabular}

Table 3. Total cost of operating the simulated system for 20 years.

\begin{tabular}{lllllll}
\hline Components & Capital (\$) & Replacement (\$) & O\&M (\$) & Fuel (\$) & Salvage (\$) & Total (\$) \\
\hline PV & $55,917,000$ & $30,959,904$ & $13,523,491$ & - & $-20,029,718$ & $80,370,672$ \\
Wind & $25,012,500$ & $13,840,154$ & $6,007,538$ & - & $-3,432,793$ & $41,427,396$ \\
Hydro & - & - & - & - & - & - \\
Generator 1 & - & - & $1,783,107$ & $5,295,827$ & $-1,535,981$ & $5,542,954$ \\
Generator 2 & - & - & $6,603,068$ & $16,531,792$ & $-180,535$ & $22,954,328$ \\
Battery & $40,268,184$ & $48,052,596$ & $5,705,420$ & - & $-17,629,630$ & $76,396,552$ \\
Converter & $4,780,000$ & $3,068,102$ & $1,040,436$ & - & $-760,985$ & $8,127,552$ \\
System & $125,977,688$ & $95,920,752$ & $34,663,060$ & $21,827,620$ & $-43,569,644$ & $234,819,456$ \\
\hline
\end{tabular}


Table 4. Annual cost of operating the simulated system.

\begin{tabular}{lllllll}
\hline Components & $\begin{array}{l}\text { Capital } \\
\text { (\$/year) }\end{array}$ & $\begin{array}{l}\text { Replacement } \\
\text { (\$/year) }\end{array}$ & $\begin{array}{l}\text { O\&M } \\
\text { (\$/year) }\end{array}$ & $\begin{array}{l}\text { Fuel } \\
\text { (\$/year) }\end{array}$ & $\begin{array}{l}\text { Salvage } \\
\text { (\$/year) }\end{array}$ & $\begin{array}{l}\text { Total } \\
\text { (\$/year) }\end{array}$ \\
\hline PV & $3,211,194$ & $1,777,961$ & 776,625 & - & $-1,150,264$ & $4,615,517$ \\
Wind & $1,436,415$ & 794,811 & 345,000 & - & $-197,138$ & $2,379,087$ \\
Hydro & - & - & - & - & - & - \\
Generator 1 & - & - & 102,400 & 304,128 & $-88,208$ & 318,320 \\
Generator 2 & - & - & 379,200 & 949,386 & $-10,368$ & $1,318,218$ \\
Battery & $2,312,516$ & $2,759,558$ & 327,650 & - & $-1,012,432$ & $4,387,292$ \\
Converter & 274,505 & 176,195 & 59,750 & - & $-43,702$ & 466,748 \\
System & $7,234,631$ & $5,508,525$ & $1,990,626$ & $1,253,514$ & $-2,502,112$ & $13,485,182$ \\
\hline
\end{tabular}

Table 5. Electrical production and quantity of components in the simulated system.

\begin{tabular}{lll}
\hline Component & Production (kWh/year) & Fraction \\
\hline PV panels & $39,623,320$ & $54 \%$ \\
Wind turbines & $28,159,934$ & $38 \%$ \\
Hydro turbine & $3,675,421$ & $5 \%$ \\
Diesel generator 1 & 512,000 & $1 \%$ \\
Diesel generator 2 & $1,503,026$ & $2 \%$ \\
Total & $73,473,696$ & $100 \%$ \\
Quantity & Value & Units \\
Excess electricity & $25,494,698$ & $\mathrm{kWh} /$ year \\
Unmet load & 0.0886 & $\mathrm{kWh} /$ year \\
Renewable fraction & 0.973 & - \\
\hline
\end{tabular}

The simulation results indicate that the proposed system can significantly reduce the diesel consumption and that the reliability of the power generation system can be improved by utilizing all recommended components (i.e., two diesel generators, one hydro turbine, 1725 wind turbines, PV panels, a converter, and batteries). Figure 4 shows the cash flow summary, and Figure 5 depicts the average electricity production. Figure 6 summarizes the proposed system's battery data. The proposed system can also save $3683 \mathrm{~kg}$ of sulfur dioxide, $40,391 \mathrm{~kg}$ of nitrogen oxide, $341 \mathrm{~kg}$ of particulate, $501 \mathrm{~kg}$ of unburned hydrocarbons, $4527 \mathrm{~kg}$ of carbon monoxide, and 1,833,841 kg of carbon dioxide waste every year.

Figure 4. Summary of cash flow.

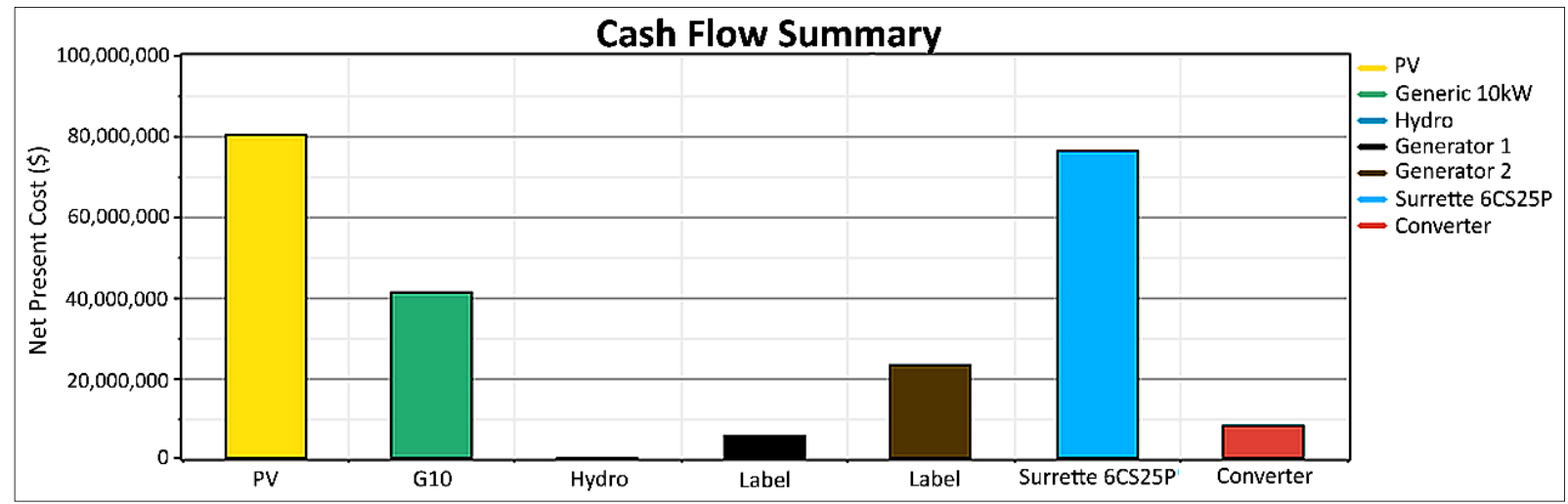


Figure 5. Average electricity production of the system.

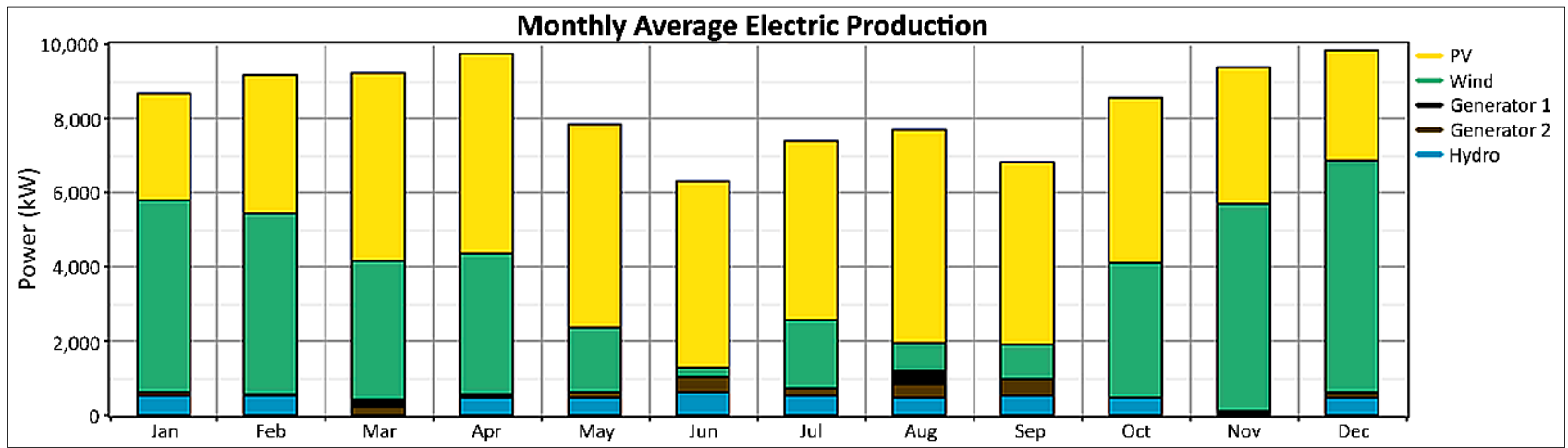

Figure 6. Frequency histogram of the batteries in the simulated system.

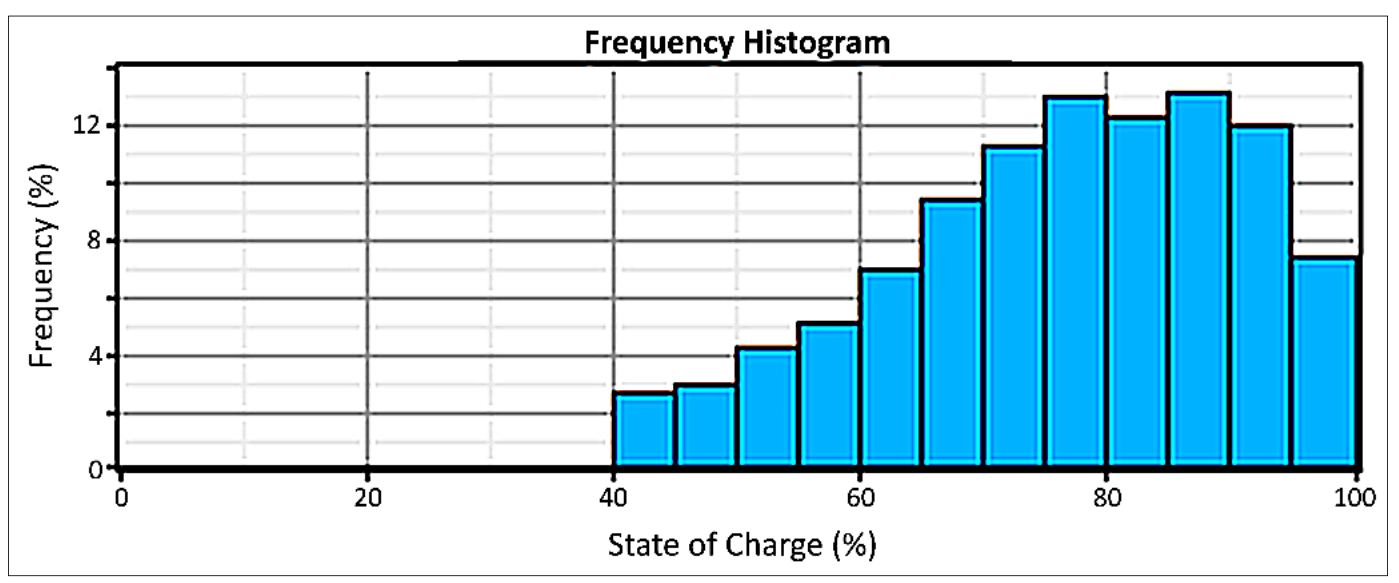

\section{Conclusions}

This study proposes the configuration of an optimized renewable power generation system for Ulleungdo Island using HOMER software. The main findings of the simulation are as follows:

- $\quad$ The suggested optimal solution consists of 1725 wind turbines (generic $10 \mathrm{~kW}$ model), 31,065 kW PV panels, a $5975 \mathrm{~kW}$ converter, 32,765 batteries (Surrette S6CS25P), and the retention of the two operating diesel generators $(8000 \mathrm{~kW}$ and $4000 \mathrm{~kW})$ and hydro turbine $(700 \mathrm{~kW})$.

- The simulation results predict an operating cost of $\$ 6,250,551$ per year, an initial capital of $\$ 125,977,680$, a total NPC of $\$ 234,819,440$, and a renewable fraction of $97 \%$ at a $\$ 0.334$ per kWh COE.

- Diesel fuel use is significantly reduced, from over $14,500,000 \mathrm{~L}$ to less than $700,000 \mathrm{~L}$, in the simulation. It also reduces other costs, such as that of transporting fuels.

The simulation indicates that installing the renewable power generation system on the island would require a huge initial capital. However, the system would significantly reduce overall costs in the long term, including operation and maintenance expenditures. In addition, as the two diesel generators provide only about $3 \%$ of the total power, the system could eliminate them and employ more battery units and other facilities instead. Therefore, this study conducts further simulations to determine an optimal renewable power generation system that omits the diesel generators. These simulations indicate that the optimal system without the generators shows similar degrees of COE $(\$ 0.348)$ and 
NPC (\$249,192,221). Thus, the diesel generators could be eliminated after their lifetimes have expired. The following points should be considered for the implementation of the system:

- Achieving the optimal level will require that gradual development plans be prepared for the island.

- Reducing the island's dependency on diesel generators will require that the reliability of its electricity system be improved and that further planning consider various other energy sources.

- After a certain level of renewable energy use has been achieved, the local government and island communities should aim to install more renewable power generation facilities as an alternative to the current diesel generators.

\section{Limitations}

This study has several limitations. First, it omits some relevant economic costs, such as that of transporting diesel [16]. Second, it fails to discuss policies and plans implemented by the South Korean government to support renewable power generation systems [17,18]. For instance, the government actively enforces its renewable portfolio standard (RPS) for local areas [19] and plans to begin managing and improving its carbon-related systems soon. Third, this study does not consider issues or theories concerning national energy industries, of which the learning effect and economies of scale are among the most significant [20,21]. Fourth, this study was conducted on a specific island in South Korea, perhaps limiting the generalizability of its results. Fifth, several renewable power generation systems, such as heat recovery facilities and geothermal power generation facilities, were not considered. Both the findings of this study and its limitations can be used as a basis for future work on similar questions.

\section{Acknowledgments}

This work was supported by the Graduate School of Innovation and Technology Management in Korea Advanced Institute of Science and Technology (KAIST). Angel P. del Pobil is supported by Generalitat Valenciana (PROMETEOII/2014/028) and by Universitat Jaume I (P1-1B2011-54).

\section{Author Contributions}

Kyeongsik Yoo and Eunil Park conducted the simulation and drafted the majority of the manuscript. Heetae Kim and Jay Y. Ohm contributed to data collection and drafting of the manuscript. Taeyong Yang, Ki Joon Kim, Hyun Joon Chang and Angel P. del Pobil contributed to analysis and interpretation of data.

\section{Conflicts of Interest}

The authors declare no conflict of interest. 


\section{References}

1. Klessmann, C.; Held, A.; Rathmann, M.; Ragwitz, M. Status and perspectives of renewable energy policy and deployment in the European Union-What is needed to reach the 2020 targets? Energ. Policy 2011, 39, 7637-7657.

2. Koo, J.; Park, K.; Shin, D.; Yoon, E.S. Economic evaluation of renewable energy systems under varying scenarios and its implications to Korea's renewable energy plan. Appl. Energy 2011, 88, 2254-2260.

3. Kim, G.; Lee, M.E.; Lee, K.S.; Park, J.; Jeong, W.M.; Kang, S.K.; Soh, J.; Kim, H. An overview of ocean renewable energy resources in Korea. Renew. Sustain. Energy Rev. 2012, 16, 2278-2288.

4. Park, N.; Yun, S.; Jeon, E. An analysis of long-term scenarios for the transition to renewable energy in the Korean electricity sector. Energy Policy 2013, 52, 288-296.

5. Hernández, T.P. 100\% Renewable Energy Islands. A Practical Case: El Hierro. In 100\% RES: A Challenge for Island Sustainable Development; Marín, C., Alves, L.M., Zervos, A., Eds.; UNESCO Center of the Canary Islands: Lisbon, Portugal, 2005; pp. 23-26.

6. Sánchez, A.B. Sustainability in the Global Tourism Industry: Good Practice Initiatives from the Private and Public Sector. El Hierro 100\% Renewable Energies. In Proceedings of the International Student Conference in Tourism Research (ISCONTOUR 2014), Tourism Research Perspectives, Krems, Austria, 5 May 2014; pp. 203-211.

7. Kim, H.; Baek, S.; Park, E.; Chang, H.J. Optimal green energy management in Jeju, South Korea-On-grid and off-grid electrification. Renew. Energy 2014, 69, 123-133.

8. Kim, G.; Jeong, W.M.; Lee, K.S.; Jun, K.; Lee, M.E. Offshore and nearshore wave energy assessment around the Korean Peninsula. Energy 2011, 36, 1460-1469.

9. Korea Meteorological Administration. Weather Information. Available online: http://web.kma.go.kr/ eng/weather/forecast/current_korea.jsp (accessed on 15 September 2014).

10. The Bank of Korea. The National Finance Information. Available online: http://www.bok.or.kr/ main/korMain.action (accessed on 15 September 2014).

11. Dursun, B. Determination of the optimum hybrid renewable power generating systems for Kavakli campus of Kirklareli University, Turkey. Renew. Sustain. Energy Rev. 2012, 16, 6183-6190.

12. Ani, V.A.; Nzeako, A.N.; Obianuko, J.C. Energy Optimization at Datacenters in Two Different Locations of Nigeria. Int. J. Energy Eng. 2012, 2, 151-164.

13. Bekele, G.; Tadesse, G. Feasibility study of small Hydro/PV/Wind hybrid system for off-grid rural electrification in Ethiopia. Appl. Energ. 2012, 97, 5-15.

14. Demiroren, A.; Yilmaz, U. Analysis of change in electric energy cost with using renewable energy sources in Gökceada, Turkey: An island example. Renew. Sustain. Energy Rev. 2010, 14, 323-333.

15. Ngan, M.S.; Tan, C.W. Assessment of economic viability for PV/wind/diesel hybrid energy system in southern Peninsular Malaysia. Renew. Sustain. Energy Rev. 2012, 16, 634-647.

16. Patterson, T.; Esteves, S.; Dinsdale, R.; Guwy, A. An evaluation of the policy and techno-economic factors affecting the potential for biogas upgrading for transport fuel use in the UK. Energy Policy 2011, 39, 1806-1816. 
17. Huh, S.; Lee, C. Diffusion of renewable energy technologies in South Korea on incorporating their competitive interrelationships. Energy Policy 2014, 69, 248-257.

18. Shin, J.; Woo, J.; Huh, S.; Lee, J.; Jeong, G. Analyzing public preferences and increasing acceptability for the Renewable Portfolio Standard in Korea. Energy Econ. 2014, 42, 17-26.

19. Kim, J.; Park, J.; Kim, H.; Heo, E. Assessment of Korean customers' willingness to pay with RPS. Renew. Sustain. Energy Rev. 2012, 16, 695-703.

20. Qiu, Y.; Anadon, L.D. The price of wind power in China during its expansion: Technology adoption, learning-by-doing, economies of scale, and manufacturing localization. Energy Econ. 2012, 34, 772-785.

21. Martinsen, T. Technology learning in a small open economy-The systems, modelling and exploiting the learning effect. Energy Policy 2011, 39, 2361-2372.

(C) 2014 by the authors; licensee MDPI, Basel, Switzerland. This article is an open access article distributed under the terms and conditions of the Creative Commons Attribution license (http://creativecommons.org/licenses/by/4.0/). 